\title{
Dynamic Evaluation and System Coordination Degree of the Integration of Artificial Intelligence and Real Economy
}

\author{
Boxun Li iD \\ Hangzhou Normal University Qianjiang College, Hangzhou, Zhejiang 524088, China \\ Correspondence should be addressed to Boxun Li; liboxun@huqc.edu.cn
}

Received 20 January 2021; Accepted 26 May 2021; Published 9 June 2021

Academic Editor: Wei Wang

Copyright (c) 2021 Boxun Li. This is an open access article distributed under the Creative Commons Attribution License, which permits unrestricted use, distribution, and reproduction in any medium, provided the original work is properly cited.

\begin{abstract}
Artificial intelligence (AI) is an important driving force of the new round of technological revolution and industrial change, and the development of a new generation of AI can help improve comprehensive national power and promote healthy and sustainable economic development. AI can promote economic development through four ways. First, AI replaces labor, expands labor connotation, increases labor supply, and enriches labor wealth; AI empowers laborers and improves labor productivity. Second, AI empowers the three industries and improves production efficiency. Third, AI creates consumer surplus and improves social welfare. Fourth, AI empowers government to correct government failure and improve government efficiency, which in turn corrects market failure and improves economic efficiency. The economic subsystem covers both quantitative and qualitative aspects of economic growth, economic structure, economic efficiency, and economic support. Environmental subsystems are divided into environmental quality, environmental pollution, and environmental protection. While using AI to promote economic development, it is also important to strengthen the research and prevention of potential risks of AI development to ensure that AI is safe, reliable, and controllable.
\end{abstract}

\section{Introduction}

Artificial intelligence (AI) is one of the main driving forces of the fourth industrial revolution, which is a general-purpose technology that must be integrated with and empower the real economy in order to play a role similar to that of steam engines, electricity, and computers in the first three industrial revolutions and to drive sustainable and healthy socioeconomic development. With the continuous development and maturity of AI technology, it is clear how to integrate AI and the real economy, promote the science and technology innovation revolution to the depth of the body that, to achieve the leapfrog development of social productivity, will directly affect the strength of national economic development, as well as the competitiveness in the world economic development, and ultimately determine the country's position in the world economic development pattern.

The concept of AI was first introduced at the Dartmouth Conference, where the scientists present defined AI as a new technical discipline: the use of machines to simulate human intelligence in terms of behavior and thought [1]. Specifically, it refers to the research and development of human thinking and behavior for the purpose of simulating the role of humans [2]. Scientists first proposed the concept of artificial intelligence 2.0 (AI2.0) in 2016, which is different from the traditional AI1.0; AI2.0 is the data intelligence innovated on the basis of the development of network technology and belongs to the new generation of AI [3]. With the rapid development and progress of many information technologies such as the Internet of Things (IoT), cloud computing, interactive Internet, and blockchain, the networking of social space has become an inevitability; the network makes the integration of physical space and social space an inevitability; the interaction between people, people and enterprises, enterprises and enterprises, and countries becomes more and more rapid and convenient; the level of social productivity is greatly improved; human society has opened the door to the era of intelligent economy [4-10]. In the future, the research field and development space of AI 
are very broad, and the research, development, and application of AI technology are the main direction and content of scientific research at present and even in a long period of time in the future. In terms of objectives, after more than 40 years of construction, AI has made remarkable achievements and significant progress from scratch, from small to large, and from weak to strong [11]. It is important to continue to strive with confidence and in accordance with the national AI development strategy and the established goals [12]. At the same time, it is also important to acknowledge the gap with developed countries and move forward. In terms of foundation, the new AI infrastructure is systematic national infrastructure construction, which is a difficult task and needs to be carefully designed to gradually realize a comprehensive layout including AI infrastructure, technology construction, and application construction, so as to lay a solid foundation for fully realizing the national AI development goals and building a strong AI country [13]. In terms of investment, the state has provided a good investment and financing environment for AI infrastructure construction and industrial development, which has played an important role in supporting the development of AI [14]. However, as major national infrastructure construction in the new era, the state needs to provide more policy support and financial investment for the new AI infrastructure to provide a fundamental guarantee for the enhancement of China's AI strength. In terms of industry, one of the important tasks of the new AI infrastructure is to develop AI industry, realize the layout of the whole industrial chain of AI basic industry, technology industry, and application industry, and provide quality services for national economic construction, social development, and people's life [15-18]. In terms of talents, high-quality AI talents at all levels are the first resource of the new AI infrastructure, and it is necessary to cultivate AI talents at all levels in multiple channels and modes [19].

All economic implementation activities such as material, spiritual, products, services, and even logistics can be called real economy, which can be subdivided into transportation, communication, agriculture, industry, manufacturing, and so on, as well as the production and services of spiritual products such as culture, sports, arts, and education. The real economy is a broad category; all economic activities and economic organizations with actual activities of production and services can be included in the real economy. The real economy is the foundation of the national economy, with the rapid development of $\mathrm{AI}$ in the new era, and the popularity of Internet technology, AI, and advanced productivity has the basis and conditions for effective integration with the real economy, which can help optimize and upgrade the structure of the real economy and drive the transformation of the real economy to intelligent, technological development.

\section{Artificial Intelligence and Real Economy Development Trend}

2.1. Industrialization Drives the Trend. It has been more than 60 years since the day the concept of AI was introduced and has entered the fast lane of development after entering the 21st century, becoming one of the important elements of the world's technological revolution, and has been applied to economic and social development in large quantities, developing and innovating more new technologies, new products, new business models, and new modes. The development trend of the integration of $\mathrm{AI}$ and the real economy is mainly reflected in the following aspects, as shown in Figure 1: first, through the use of big data, AI can quickly and accurately process huge information and data, so as to reduce the errors in decision-making caused by errors in data analysis and make economic development more stable [20]; second, the effective allocation of resources through intelligent control can realize the precision of production and improve the efficiency and benefits of production; third, through the effective use of electric energy, it can achieve commercial ecology, reduce carbon emissions, and achieve energy conservation and environmental protection [21]. In fact, the full use of AI can realize the transformation and upgrading of traditional real economy, and the deep integration of AI and traditional real economy can be realized through the use of big data to promote product elements and supply structure [22].

The economic system has been improved and the market economy has developed rapidly, but it still has not reached the level of modern market economy development, and it is still necessary to build and improve the modernized economic system on the basis of vigorous development of the real economy [23]. National economic security and macroeconomic development stability are the basis for the construction of a modernized economic system, while the availability of a sound industrial system is a key factor in the construction of a modernized economic system. At the same time, we must also optimize the industrial structure and rationalize the layout of the economic system, so that we can truly cultivate a mature economic market to achieve highquality economic improvement [24]. The key point of integration of AI with the real economy is to effectively enhance the intelligence content of the real economy so that it can be applied in agriculture, industry, manufacturing, and tertiary industries in a focused manner. This must achieve two requirements: first, to adjust the original industrial structure from low level to high level to achieve innovation in product value; second, to optimize and upgrade the growth mode of the real economy, breaking through the original idea of expanding the quantitative scale to achieve growth, but constantly upgrading product quality and performance to achieve growth and maximize revenue while reducing costs [25].

2.2. Transformation of Manufacturing Development. The starting point of traditional manufacturing industry is OEM, which is at the bottom of the "smile curve" of the manufacturing industry, with backward production equipment, high production cost, low intelligence, and the most tiring and dirty work but the least rewarding and the least technical content, and many key technologies and core technologies are monopolized by enterprises in Europe, America, Japan, and other developed countries. This makes 


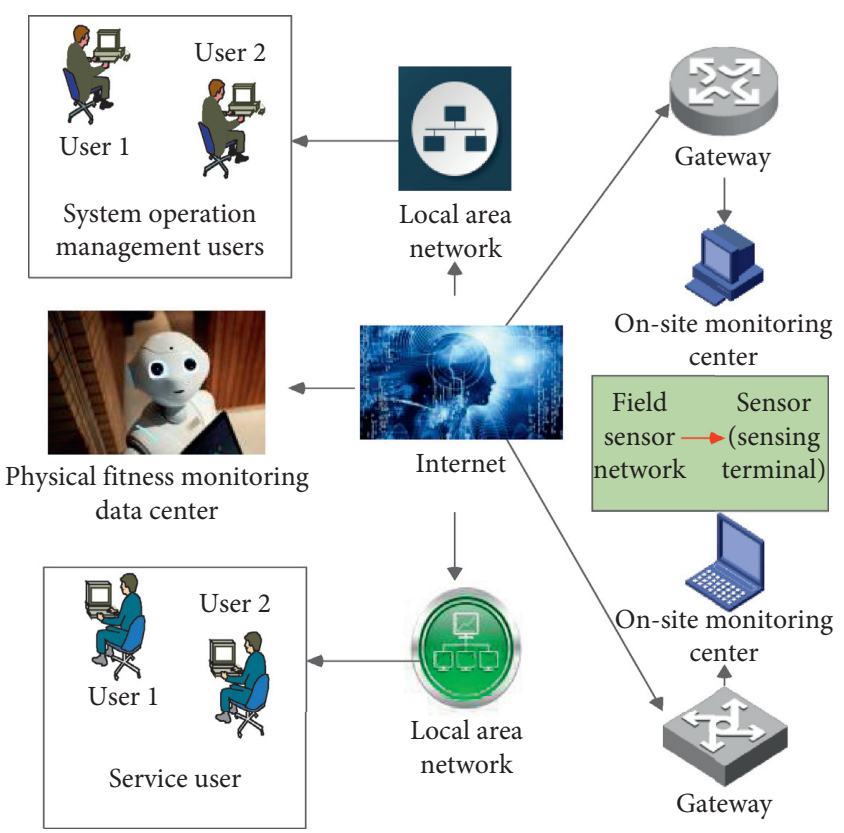

Figure 1: Artificial intelligence (AI) and real economy development trends.

the development of traditional manufacturing transformation have to face many difficulties and problems [26]. At the same time, the development of the emerging manufacturing industry is still in the early stage of small-scale development, and it is a long way to go to become a modern manufacturing power. From the current situation of international market competition, it can be seen that the core competitiveness of industrial manufactured products in the international market is mainly low prices, which weakens the overall profitability of the manufacturing industry, as shown in Figure 2. In fact, the more intelligent the manufacturing industry is, the more competitive the real economy is, in order to have the opportunity to continuously improve its position in the global industrial value chain. Therefore, the key to accelerating the transformation and upgrading of the manufacturing industry lies in the ability to achieve intelligent transformation and upgrading.

Traditional service industries such as retail, tourism, and catering occupy a great proportion of the service industry, but the application of AI technology in them is subject to many restrictions and has not been commonly used. The main reason for this situation is that the traditional service industry is relatively backward in terms of business methods and service means. At the same time, logistics, finance, commerce, information, and other service industries in the service industry occupy a relatively small proportion of the use of AI, which is not optimistic. In summary, the transformation and upgrading of the service industry cannot be separated from the driving force of AI technology. Although the development of the sharing economy and the promotion of IoT commerce have eased the downward development pressure of the service industry to a certain extent, the existence of such limited problems as the weak operational management capability and the lagging development of
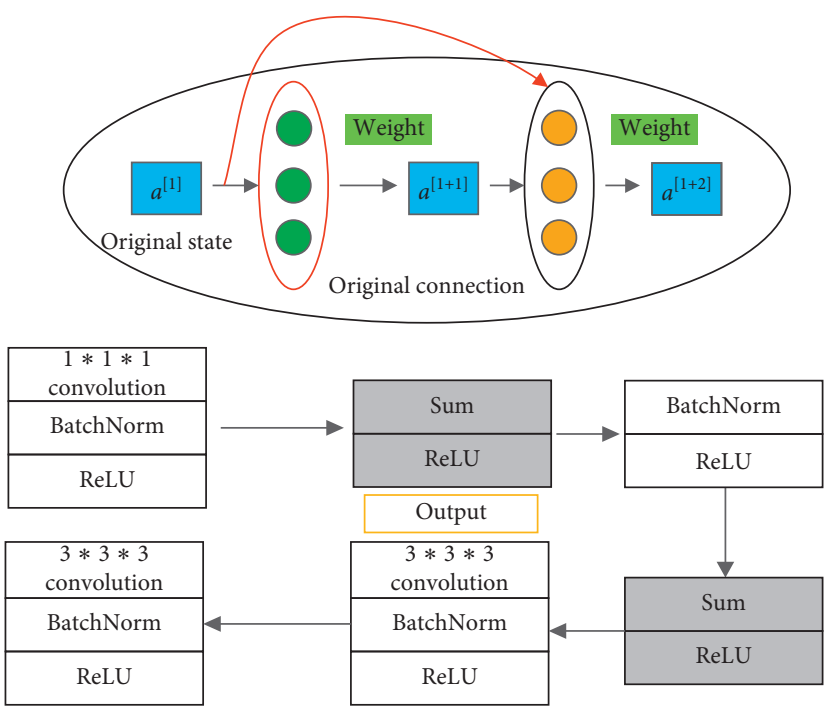

FIGURE 2: Core competence for manufacturing industry.

occupational standards in the development of these two models has affected the quality of development. Therefore, the transformation of the development of service industry must accelerate the use of AI technology and realize the integration of AI and service industry in order to truly meet the needs of market competition and realize the transformation and development of modern service industry.

2.3. The Development of AI Technology. From the development and application of AI technology, it can be seen that the AI industry in the first-tier cities such as North, Guangzhou, Shenzhen, and other relatively developed economies is more widely distributed and more AI technology is used, forming a certain AI technology focus effect. However, the development of AI in these first-tier cities is still at a low level of popularity; only those very large enterprises, leading enterprises, or backbone enterprises in the use of more, accounting for more than $85 \%$ of the total number of enterprises in small- and medium-sized enterprises, are rarely involved, which directly limits the scale effect of AI devices, reducing the advantages of seamless docking and smooth communication of AI technology. To sum up, the development of the real economy needs the addition of AI, and the integration of $\mathrm{AI}$ into the real economy is also an inevitable choice for economic development. The deep integration of AI and manufacturing should start from four aspects, such as product development, production, sales, and service. The energy subsystem is divided into three aspects of energy scale, energy consumption, and energy efficiency, covering the process of energy subsystem from input and output to consumption and considering the efficiency of energy use.

From the perspective of product development, AI technology can access a large amount of relevant information and data both at home and abroad and build a platform for product development more quickly, as shown in Figure 3. After the intelligent platform analyzes and learns the collected data and information, it can quickly research 


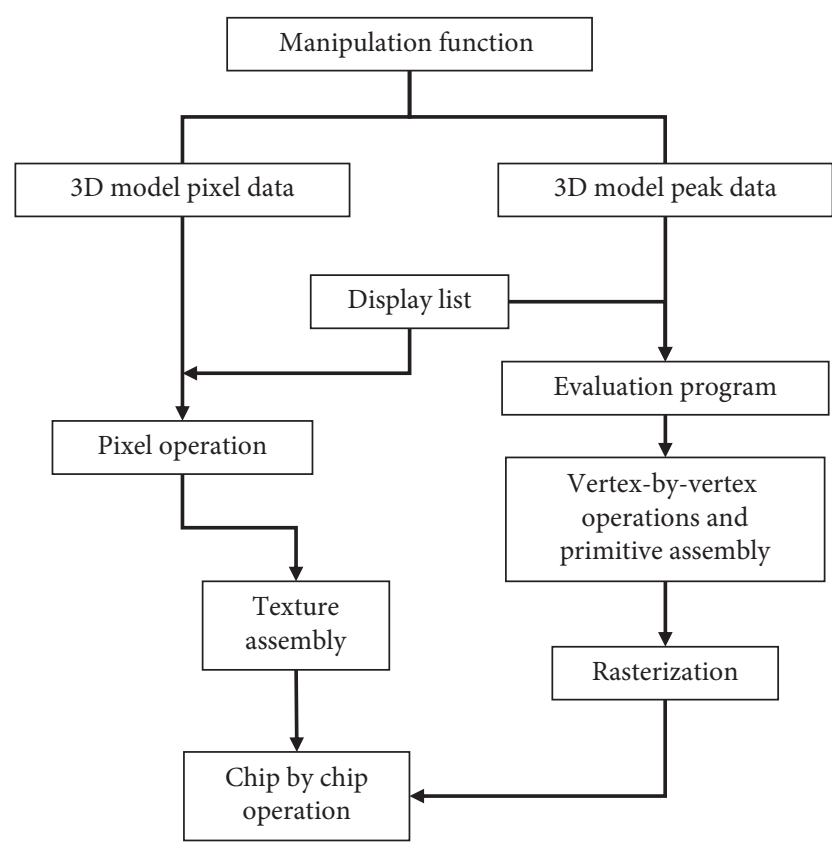

FIgURE 3: Deep integration of AI and manufacturing.

and design various $\mathrm{R} \& \mathrm{D}$ texts to meet the needs of social production and life. From the perspective of product production, AI technology is able to deeply inspect products and work nonstop 24 hours a day while ensuring product quality. From the perspective of product sales, AI can analyze and calculate the macroenvironment of the market, determine the most reasonable and competitive price of products, and ensure the competitiveness of the market while ensuring maximum profits, so as to provide high-quality advice and suggestions for product manufacturers and customers. From the point of view of product service, the application of AI to enterprise intelligent services can, to a certain extent, achieve round-the-clock service and give customers corresponding intelligent technical support. The key to the development and growth of the real economy is in the manufacturing industry, and the deep integration of AI technology and manufacturing industry can promote the transformation, upgrading, and optimization of the manufacturing industry and realize the healthy and sustainable development of the manufacturing industry.

AI technology is fully applied to agriculture, forestry, animal husbandry, fisheries, and other broad agricultural industries to develop corresponding intelligent agricultural production equipment to realize the intelligence, technology, and modernization of traditional agriculture. It is a large agricultural country, in thousands of years of farming civilization, human and semimechanized labor are the core of labor, and the annual harvest depends more on the climate. With the development of socialist market economy, more and more rural laborers are working in the cities, and agricultural laborers are reduced in large numbers. And the use of AI technology can significantly reduce the manpower requirements of agricultural production while improving the efficiency and effectiveness of production. In fact, in the macroenvironment that the era of big data has arrived, AI can be used in agriculture to fully introduce big data technology to make a comprehensive analysis of market demand and make scientific decisions. The production of agricultural and sideline products and the production of animal husbandry are quantified, and point-to-point targeted sales are carried out through the Internet, so as to optimize the allocation of agricultural production and marketing resources in different regions and realize the integration of agricultural production and supply and marketing.

\section{Results and Analysis}

3.1. System Coordination Evaluation Model. The integrated coordination model is based on the assumption that the three subsystems of energy, economy, and environment are of equal importance and have the same impact. The model examines the coordinated development of these three subsystems from a holistic perspective.

$$
\begin{gathered}
U=\frac{\sqrt{\cap_{q}^{i} X_{I I}}}{x_{i}}, \\
E_{x_{I I}}=\sum_{i=1}^{q} \chi_{i i},
\end{gathered}
$$

where $E_{i}$ denotes a subsystem $i$ in the $3 E$ system, $E_{1}, E_{2}$, and $E_{3}$ denote the development levels of the energy subsystem, the economic subsystem, and the environmental subsystem, respectively, $x_{i j}$ denotes the jth evaluation index of subsystem $i$, and $X$ is the corresponding weight of this evaluation index. From equation (1), it is easy to calculate and is essentially the geometric average of the development level of the three subsystems, and there is no specific requirement for the value of the comprehensive development level of the system to be positive, negative, or zero. It can reflect the functional degree of the development level of the whole $3 E$ system, but it cannot reflect the submission degree of the subsystems matching each other's development level.

The distance-based coordination model assumes the premise that the combined development levels of the energy, economic, and environmental subsystems must all be positive and are calculated as

$$
E_{i i}=\sum_{i=1}^{q} \chi_{i i} \times \delta_{i j},
$$

where $W$ denotes the degree of matching of development levels among subsystems; $V$ denotes the functional degree of the overall development level of the $3 E$ system, which is essentially a weighted average of the development levels of each subsystem.

When evaluating the degree of coordination between the energy subsystem and the economic subsystem,

$$
Q_{i i}=\left\{\frac{\sum_{i=1}^{q} E_{i i} \times E_{i j}}{E_{1}+E_{2}}\right\}^{k+1},
$$




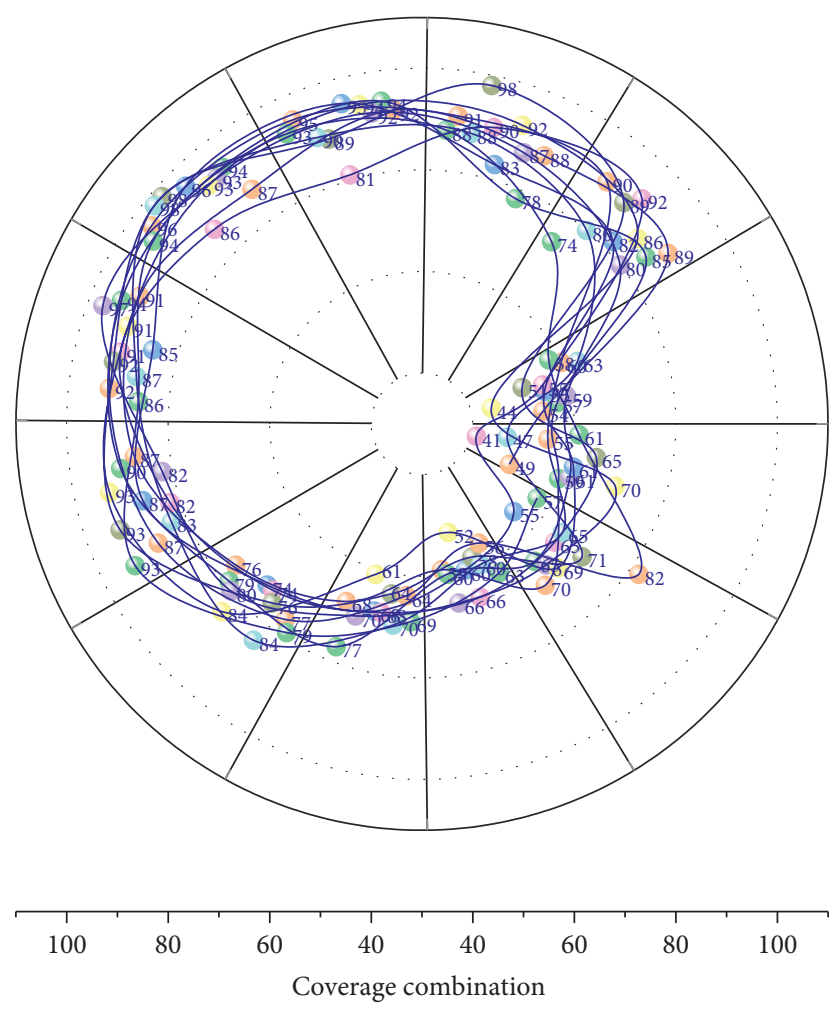

FIgURE 4: Variation of system coordination $U$.

where $k(k>2)$ is the coordination coefficient, which is generally taken as 2; $E_{1}$ and $E_{2}$ denote the weights of the subsystems, respectively. When measuring the coordination degree among the three systems, that is, the total coordination degree of the $3 E$ system, $W$ and $V$ in equation are expanded according to the system covariance theory and the discretization principle, respectively:

$$
Q_{i i}=\frac{\alpha E_{1}+\beta E_{2}}{\left\{S_{i} / S+Q_{j}\right\}^{\delta}} .
$$

The evaluation model reflects both the matching degree and the functional degree among the subsystems of the $3 E$ system, and the calculation is relatively easy. When the comprehensive development level of each subsystem is equal, the $3 E$ system coordination degree $U$ reaches the maximum, which means that the development status of the $3 E$ system is high-quality coordination, as shown in Figure 4.

The change-based coordination model is a dynamic evaluation model. This dynamic evaluation is reflected in the fact that it evaluates the whole $3 E$ system coordination by the degree of relative change in the rate of development of subsystems and subsystems. The system coordination degree $U_{i}$ of the subsystem is calculated as

$$
U_{i}= \begin{cases}e^{\left(\mathrm{d} Q_{i} / \mathrm{d} t-\mathrm{d} Q_{j} / \mathrm{d} t\right)}, & \frac{\mathrm{d} Q_{i}}{\mathrm{~d} t}<\frac{\mathrm{d} Q_{j}}{\mathrm{~d} t}, \\ e^{\left(\mathrm{d} Q^{*} / \mathrm{d} t-\mathrm{d} Q_{j} / \mathrm{d} t\right)}, & \frac{\mathrm{d} Q^{*}}{\mathrm{~d} t}<\frac{\mathrm{d} Q_{j}}{\mathrm{~d} t},\end{cases}
$$

where $\mathrm{d} E^{*} / \mathrm{d} t$ is the $3 E$ system development rate and $E^{*}$ denotes the $3 E$ system development level. $u_{i}$ takes values in the range of $U_{\mathrm{i}}$ belongs to $(0,1]$. The total coordination degree $U$ of the $3 E$ system is calculated as

$$
U=\frac{\sqrt{\cap_{i=1}^{Q} U_{i}}}{Q_{i j}} .
$$

From the equation, we can see that $U$ takes the value range of $U$ belongs to $(0,1]$, and the larger the value of $U$, the better the coordination state of the $3 E$ system. In addition to the total coordination degree of the $3 E$ system, the evaluation can also examine the coordination degree between two subsystems, which is more comprehensive. However, it uses a differential algorithm to calculate the coordination degree between two subsystems, which is more difficult and complicated than the other two evaluation models mentioned above. Meanwhile, it focuses on the matching degree of development speed between subsystems, as shown in Figure 5, which lacks the function of reflecting the overall development level of the system.

In this paper, we refer to the evaluation metrics used in the current literature on the evaluation of provincial $3 E$ system coordination.

(1) The target level is set as the provincial energyeconomy-environment ( $3 E$ ) system coordination degree $U$.

(2) The criterion level is divided into three categories according to the number of subsystems, namely, the energy subsystem development level $1 E$, the 


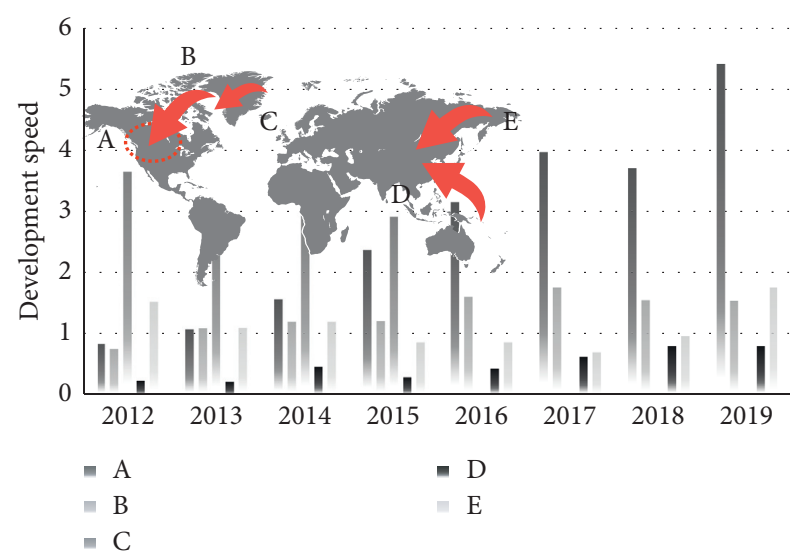

FIGURE 5: Matching of development speed between subsystems.

economic subsystem development level $2 E$, and the environmental subsystem development level $3 E$. The environmental subsystem is divided into environmental quality, environmental pollution, and environmental protection, which evaluates the level of environmental development from three aspects: the current state of the environment, the current state of pollution, and the inputs made to protect the environment.

(3) In accordance with the subcriteria level, representative evaluation indicators were selected based on the existing literature on $3 E$ system coordination evaluation and consultation with relevant experts, as shown in Figure 6, 9 indicators for evaluating the energy subsystem, 11 indicators for evaluating the economic subsystem, and 9 indicators for evaluating the environmental subsystem, a total of 29 indicators.

In the evaluation and analysis of the provincial $3 E$ system coordination, in order to eliminate the influence of dimensionality and ensure the comparability of the evaluation results, as shown in Figure 7, this paper uses the polarization method to dequantize the original data $x_{i j}$.

$$
U=\left\{\begin{array}{l}
x_{i j}=\frac{\min \left(x_{i j}\right)-x_{i j}}{\max \left(x_{i j}\right)-\min \left(x_{i j}\right)}, \\
x_{i j}=\frac{1}{1+x_{i j}}, \\
x_{i j}=\frac{x_{i j}-\min \left(x_{i j}\right)}{\max \left(x_{i j}\right)-\min \left(x_{i j}\right)} .
\end{array}\right.
$$

$\operatorname{Max}\left(x_{i j}\right)$ and $\min \left(x_{i j}\right)$ are the maximum and minimum values of evaluation index $x_{i j}$, respectively, and $M$ is the average value of evaluation index $x_{i j}$.

In order to calculate the development level of the three subsystems of energy, economy, and environment, this paper uses the coefficient of variation weighting method to
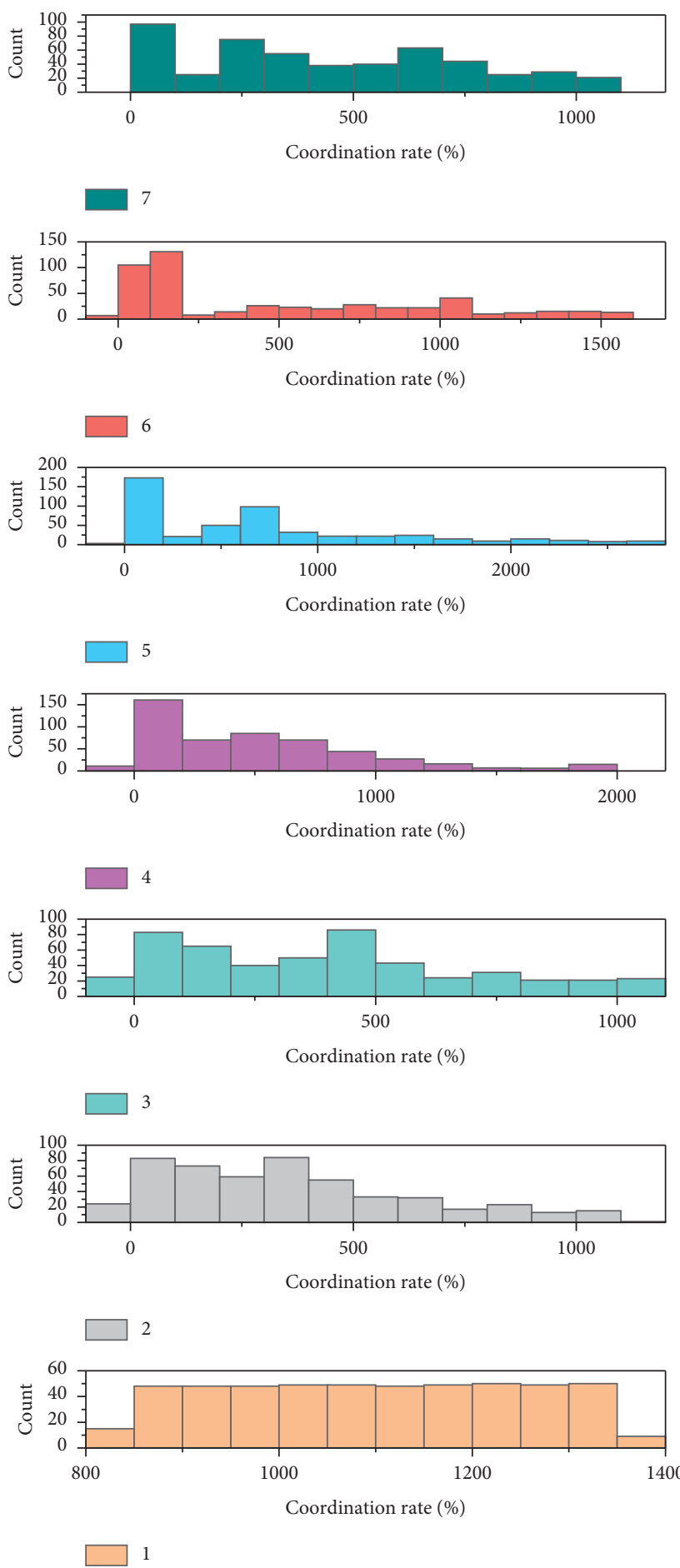

Figure 6: Selection of $3 E$ sytem coordination.

calculate the weights of each indicator according to the three subsystems of energy, economy, and environment. The basic idea of the coefficient of variation weighting method is that when the coefficient of variation of an indicator is more different from that of other indicators, the indicator can better reflect the gap between the evaluated objects, and the indicator is given a larger weight; conversely, it should be given a smaller weight. From the comparison of the weight 


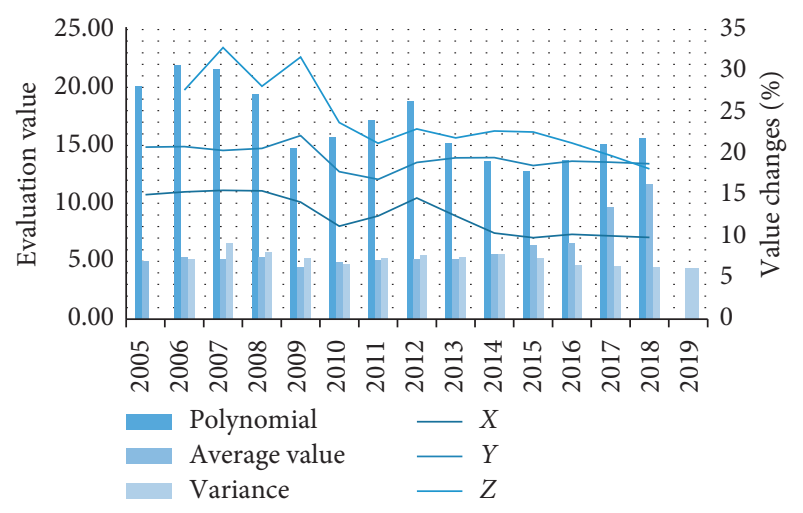

FIgURE 7: Evaluation and analysis of provincial $3 e$ system coordination.

of each indicator, it can be inferred that the indicator with a larger weight has a greater influence on the coordinated development of $3 E$ system; on the contrary, it has a smaller influence on the coordinated development of $3 E$ system.

3.2. Analysis of Experimental Results. There are 3 indicators in the energy subsystem with weights greater than the average value $(11.11 \%)$, as shown in Figure 8 , in descending order: electricity generation, investment in energy industry, and investment in fixed assets in energy industry of stateowned economy, with weights of $20.08 \%, 18.58 \%$, and $18.55 \%$, respectively. It means that these three indicators in the energy subsystem are relatively different among the 30 provinces and regions, while the remaining six indicators do not vary much among the 30 provinces and regions. Combined with the meaning of coordinated development of the $3 E$ system, improving energy use efficiency and developing green energy require financial support, and achieving stable energy supply and demand needs to be considered from the supply side. The more intelligent manufacturing is, the more likely the real economy is. It is more competitive and has the opportunity to continuously improve its position in the global industrial value chain. The two indicators of energy industry investment and the amount of investment in fixed assets in the energy industry of the state-owned economy, which are sources of financial support, and the amount of electricity generation, which is the main supply side, differ significantly among the 30 provinces. Therefore, the above weighting of the energy subsystem indicator layer is more objective and reasonable. Therefore, the abovementioned weight assignments for each subsystem indicator layer are more objective and reasonable.

The highest year-on-year growth rate was $17.64 \%$ in 2010; this indicates that the overall level of provincial $3 E$ system coordination was on the rise, and the year 2010 was the turning point, as shown in Figure 9, when the $3 E$ system coordination level changed from a severe disorder level to a moderate disorder level. 2010 was the closing year of the Eleventh Five-Year Plan. The year 2010 was the closing year of the 11th Five-Year Plan, so it can be concluded that it is the strict implementation of the 11th Five-Year Plan by the provinces that effectively promoted the development of

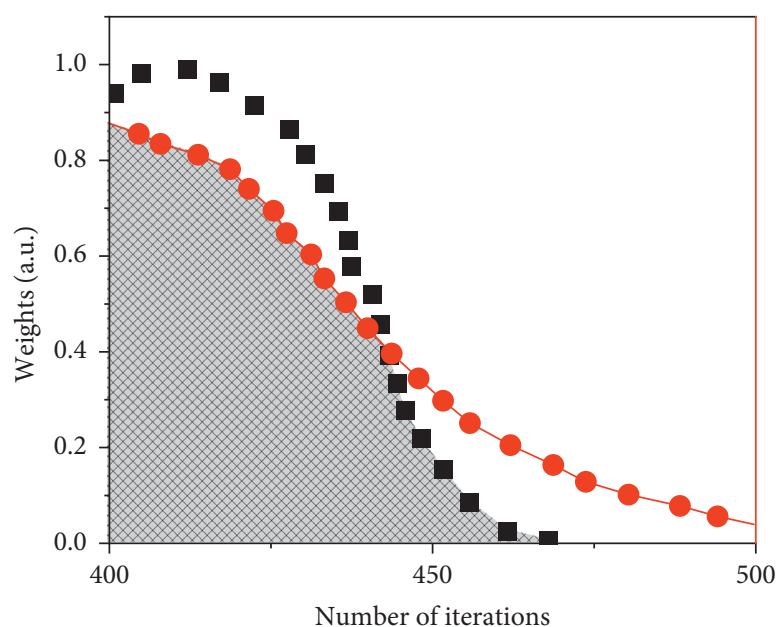

$\rightarrow$ Simulation

Real data

FIGURE 8: Variation of weights in the subsystem.

provincial $3 E$ system coordination from quantitative to qualitative change. If the average annual growth rate of $7.25 \%$ is maintained, the provincial $3 E$ system coordination will reach a turning point of 0.53 by 2015 , and the $3 E$ system coordination level will develop from a moderate disorder level to a mild disorder level, while 2015 is the closing year of the 13th Five-Year Plan. The year 2015 is the closing year of the 13th Five-Year Plan.

In the economic subsystem, there are six indicators with higher weight than the average value $(9.09 \%)$, as shown in Figure 10, in descending order, namely, industrial value added, total retail sales of consumer goods, social fixed asset investment, value added of tertiary industry as a percentage of GDP, per capita gross regional product, and local general budget revenue as a percentage of GDP, with weights of $14.26 \%, 13.20 \%, 11.07 \%, 10.63 \%, 10.21 \%$, and $10.15 \%$, respectively. The difference algorithm is used to calculate the coordination between two subsystems. This is harder and more complex than the other two evaluation models above.

It indicates that these 6 indicators in the economic subsystem are relatively different among the 30 provinces, while the other remaining 5 indicators are less different among the 30 provinces. Combined with the meaning of coordinated development of the $3 E$ system, achieving the goal of economic development requires solid government financial support, reasonable industrial structure, innovation and popularization of relevant advanced technologies, and steady growth of social consumption capacity, and the above-mentioned 6 indicators with higher-than-average weights cover exactly these requirements. Therefore, the above-mentioned weighting of the indicators of the economic subsystem is also objective and reasonable. Similarly, there are three indicators in the environmental subsystem with higher-than-average weights $(11.11 \%)$, in descending order, namely, water resources per capita, total investment in environmental pollution control, and completed investment in industrial pollution control, with weights of $27.63 \%$, $19.84 \%$, and $18.79 \%$, respectively. It means that these 3 


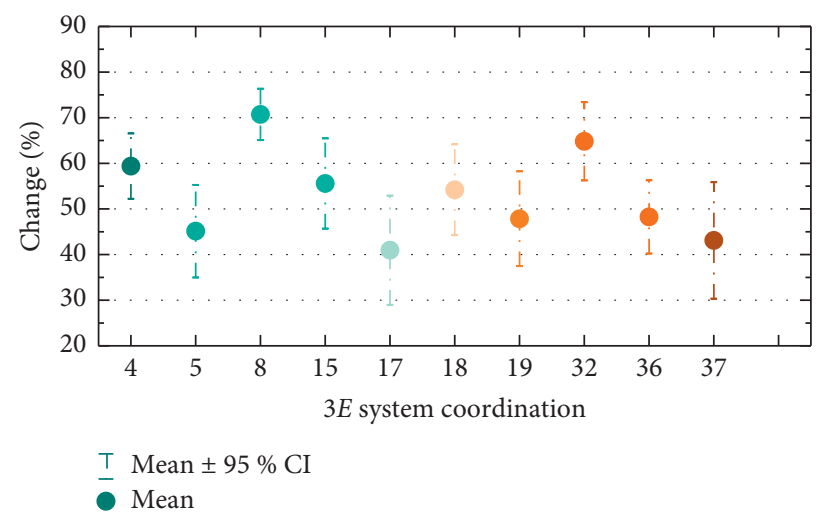

Figure 9: Overall change in provincial $3 E$ system coordination.

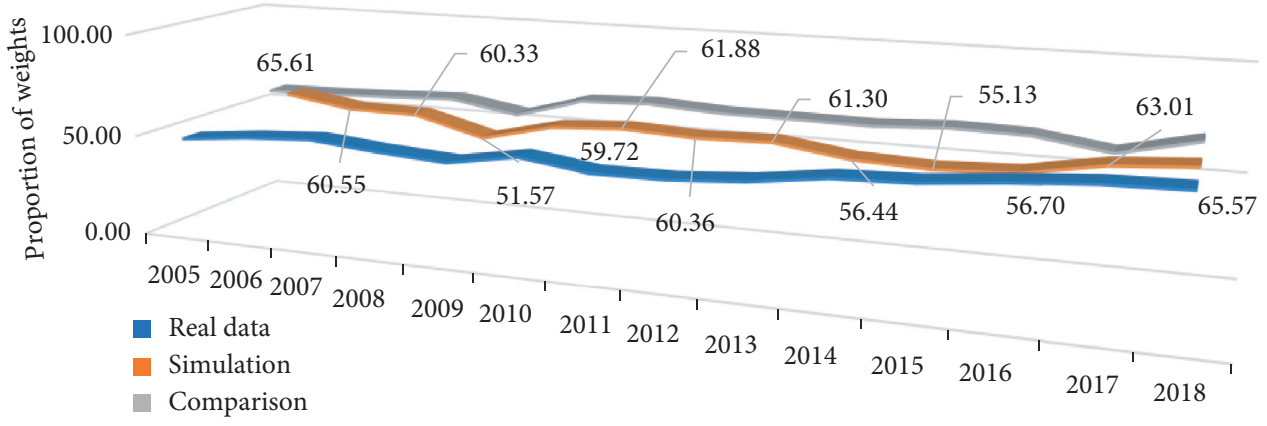

FIgURe 10: Proportion of weights in the economic subsystem.

indicators in the energy system are the ones that differ more among the 30 provinces, while the other 6 remaining indicators do not differ much among the 30 provinces. It means that these 3 indicators in the environmental subsystem are more different among 30 provinces, while the remaining 6 indicators are less different among 30 provinces. Combined with the meaning of the $3 E$ system coordinated development, the environmental protection goal cannot be achieved without the treatment of environmental pollution, and to treat it, we need to invest money. At present, the overall environmental pollution remediation efforts are increasing, but the differences in investment efforts between regions are still large, the water resources problem has been one of the factors troubling the sustainable economic and social development, and the differences in water resources between regions have aggravated the imbalance of regional development.

The coordination degree of the provincial $3 E$ system has shown an increasing trend over time, and its coordination degree value increased from 0.28 in 2006 to 0.49 in 2014, with an increase of about $75 \%$ and an average annual growth rate of $7.25 \%$. The possible reason is that, with the implementation of the 11th Five-Year Plan in 2006 on the comprehensive implementation of the scientific concept of development and accelerating the pace of building a resource-saving and environment-friendly society, the attention to the coordinated development of energy, economy, and environment has been strengthened and effective measures have been taken. There are 2 lowest year-on-year growth rates, in 2009 and 2014, both of which are the same as the previous year. Possible reasons are mainly as follows: 2009 was affected by the global financial crisis and economic development was seriously challenged, while the negative effects of energy depletion and environmental pollution generated by years of rough economic growth model also emerged; 2014 is mainly a period of active deepening reform, which will inevitably have an impact on the three subsystems of energy, economy, and environment.

\section{Conclusion}

Based on the construction of the provincial $3 E$ system coordination evaluation index system and coordination evaluation model, this paper measures and analyzes the coordination degree of provincial $3 E$ system by using the annual data of 30 provinces from 2006 to 2014 and obtains the following main conclusions: (1) In terms of average level, the $3 E$ system coordination in the province from 2006 to 2014 showed an increasing trend and a large magnitude; and with 2010 as a turning point, the $3 E$ system coordination level changed from a serious disorder level to a moderate disorder level. (2) By province, from the value of $3 E$ system coordination of each province, the development of each province varies greatly. Shandong Province leads the country in the fluctuation of $3 E$ system coordination; the fluctuation of $3 E$ system coordination in five provinces, namely, Beijing, Shanxi, Shanghai, Jiangsu, and Guangdong, is smaller; except for the above-mentioned provinces, the 
fluctuation of $3 E$ system coordination in the remaining provinces is also relatively large. However, judging from the status level of $3 E$ system coordination in each province (with the median as the reference), the provincial $3 E$ system coordination is in a state of dysfunction, and most of the provinces are in a state of serious dysfunction.

\section{Data Availability}

The data used to support the findings of this study are available from the corresponding author upon request.

\section{Conflicts of Interest}

The authors declares no conflicts of interest.

\section{References}

[1] H. Zhang, X. Liu, and X. Ma, “The preparation of felodipine/ zein amorphous solid dispersions and in vitro evaluation using a dynamic gastrointestinal system," Pharmaceutical Development and Technology, vol. 25, no. 10, pp. 1226-1237, 2020.

[2] Q. Bian-bian, Z. Ji-ping, Z. Zai-xiang, and S. Hui, "Establishing a dynamic ergonomic evaluation index system for complex product designs based on the theory of product life cycle," International Journal of Industrial Ergonomics, vol. 69, pp. 153-162, 2019.

[3] S. Ren, K. He, R. Girshick, and J. Sun, "Faster R-CNN: towards real-time object detection with region proposal networks," IEEE Transactions on Pattern Analysis and Machine Intelligence, vol. 39, no. 6, pp. 1137-1149, 2017.

[4] M. F. Byrne, N. Chapados, F. Soudan et al., "Real-time differentiation of adenomatous and hyperplastic diminutive colorectal polyps during analysis of unaltered videos of standard colonoscopy using a deep learning model," Gut, vol. 68, no. 1, pp. 94-100, 2019.

[5] O. Abdeljaber, O. Avci, S. Kiranyaz, M. Gabbouj, and D. J. Inman, "Real-time vibration-based structural damage detection using one-dimensional convolutional neural networks," Journal of Sound and Vibration, vol. 388, no. 388, pp. 154-170, 2017.

[6] A. Ignatov, "Real-time human activity recognition from accelerometer data using convolutional neural networks," Applied Soft Computing, vol. 62, pp. 915-922, 2018.

[7] D. Tegunov and P. Cramer, "Real-time cryo-electron microscopy data preprocessing with warp," Nature Methods, vol. 16, no. 11, pp. 1146-1152, 2019.

[8] C. F. Baumgartner, K. Kamnitsas, J. Matthew et al., "SonoNet: real-time detection and localisation of fetal standard scan planes in freehand ultrasound," IEEE Transactions on Medical Imaging, vol. 36, no. 11, pp. 2204-2215, 2017.

[9] E. Romera, J. M. Alvarez, L. M. Bergasa, and R. Arroyo, "ERFNet: efficient residual factorized ConvNet for real-time semantic segmentation," IEEE Transactions on Intelligent Transportation Systems, vol. 19, no. 1, pp. 263-272, 2018.

[10] J. Zhang and S. Singh, "Low-drift and real-time lidar odometry and mapping," Autonomous Robots, vol. 41, no. 2, pp. 401-416, 2017.

[11] Y. He, G. J. Mendis, and J. Wei, "Real-time detection of false data injection attacks in smart grid: a deep learning-based intelligent mechanism," IEEE Transactions on Smart Grid, vol. 8, no. 5, pp. 2505-2516, 2017.
[12] J. DelPreto, A. F. Salazar-Gomez, S. Gil, R. Hasani, F. H. Guenther, and D. Rus, "Plug-and-play supervisory control using muscle and brain signals for real-time gesture and error detection," Autonomous Robots, vol. 44, no. 7, pp. 1303-1322, 2020.

[13] R. Maini and G. Dhiman, "Impacts of artificial intelligence on real-life problems," International Journal of Advance Research and Innovative Ideas in Education, vol. 4, no. 1, pp. 291-295, 2018.

[14] A. Ebigbo, R. Mendel, A. Probst et al., "Real-time use of artificial intelligence in the evaluation of cancer in barrett's oesophagus," Gut, vol. 69, no. 4, pp. 615-616, 2020.

[15] S.-H. Park, H.-M. Park, K.-R. Baek, H.-M. Ahn, I. Y. Lee, and G. M. Son, "Artificial intelligence based real-time microcirculation analysis system for laparoscopic colorectal surgery," World Journal of Gastroenterology, vol. 26, no. 44, pp. 6945-6962, 2020.

[16] D. Tang, W. Du, L. Shekhtman et al., "Predictability of real temporal networks," National Science Review, vol. 7, no. 5, pp. 929-937, 2020.

[17] S. De Vito, E. Esposito, M. Salvato et al., "Calibrating chemical multisensory devices for real world applications: an in-depth comparison of quantitative machine learning approaches," Sensors and Actuators B: Chemical, vol. 255, pp. 1191-1210, 2018.

[18] Q. Huang and Z. Zeng, "A review on real-time 3D ultrasound imaging technology," BioMed Research International, vol. 2017, Article ID 6027029, 20 pages, 2017.

[19] Y. Mori, S.-E. Kudo, M. Misawa et al., "Real-time use of artificial intelligence in identification of diminutive polyps during colonoscopy," Annals of Internal Medicine, vol. 169, no. 6, pp. 357-366, 2018.

[20] C. Sánchez-Sánchez and D. Izzo, "Real-time optimal control via deep neural networks: study on landing problems," Journal of Guidance, Control, and Dynamics, vol. 41, no. 5, pp. 1122-1135, 2018.

[21] W. Xu, A. Chatterjee, M. Zollhofer et al., "Mo2Cap2: real-time mobile 3D motion capture with a cap-mounted fisheye camera," IEEE Transactions on Visualization and Computer Graphics, vol. 25, no. 5, pp. 2093-2101, 2019.

[22] D. Dai, C. Sakaridis, S. Hecker, and L. Van Gool, "Curriculum model adaptation with synthetic and real data for semantic foggy scene understanding," International Journal of Computer Vision, vol. 128, no. 5, pp. 1182-1204, 2020.

[23] B. Zhang, L. Wang, Z. Wang, Y. Qiao, and H. Wang, "Realtime action recognition with deeply transferred motion vector CNNs," IEEE Transactions on Image Processing, vol. 27, no. 5, pp. 2326-2339, 2018.

[24] N. Krishnaraj, M. Elhoseny, M. Thenmozhi, M. M. Selim, and K. Shankar, "Deep learning model for real-time image compression in internet of underwater things (IoUT)," Journal of Real-Time Image Processing, vol. 17, no. 6, pp. 2097-2111, 2020.

[25] Q. Dou, L. Wei, D. R. Magee, and A. G. Cohn, "Real-time hyperbola recognition and fitting in GPR data," IEEE Transactions on Geoscience and Remote Sensing, vol. 55, no. 1, pp. 51-62, 2017.

[26] C. Kapeller, H. Ogawa, G. Schalk et al., "Real-time detection and discrimination of visual perception using electrocorticographic signals," Journal of Neural Engineering, vol. 15, no. 3, p. 36001, 2018. 